\title{
RELATO DE EXPERIÊNCIA DE INTERCÂMBIO BRASIL/CANADÁ: CONHECENDO O PROGRAMA INTERDISCIPLINAR DE INTERVENÇÃO FAMILIAR
}

\author{
Experience Report of the Brazil/ Canada Exchange: \\ Knowing the Interdisciplinary Program of Family Intervention \\ Relato de Experiencia de Intercambio Brasil/ Canadá: \\ Conociendo el Programa Interdisciplinario de Intervención Familiar
}

lêda Maria Ávila Vargas Dias

Rosangela da Silva Santos

\begin{abstract}
Resumo
0 presente artigo consiste no relato de experiência da visita de estudo realizada ao Canadá através da Bourse de Complément de Spécialisation do Faculty Enrichment Program in Brazil, concedida pela Embaixada do Canadá no Brasil. Descreve as atividades realizadas durante a visita e apresenta o Programa Interdisciplinar de Intervenção Precoce. Este programa baseia-se na experiência de intervenção por meio da abordagem inscrita na corrente da educação para a saúde, reconhece a eficácia da intervenção profissional estreitamente ligada ao grau de colaboração estabelecido entre pais e profissionais e enfatiza a importância de a família-enfermeira desenvolver e compartilhar conhecimentos e experiências. À guisa da conclusão, pode-se de dizer que, para além do alcance dos objetivos traçados na proposta da visita, inúmeros foram os ganhos advindos no desenvolvimento dessa atividade.
\end{abstract}

Palavras-chave:

Intercâmbio Educacional Internacional. Educação de Pós-graduação em Enfermagem. Equipe de Assistência ao Paciente.

\begin{abstract}
The present article consists in an experience report about the visit of study realized in Canadá through the Bourse de Complément de de Spécialisation of the Faculty Enrichment Program in Brazil, granted by the Canada Embassy in Brazil. It describes the activities carried though during the visit and presents the Interdisciplinary Program of Precocious Intervention. This program is based on the experience of the intervention by the enrolled boarding way in the education chain for the health, it recognizes the effectiveness of the professional intervention narrowly connected to the degree of contribution established between parents and professionals and emphasizes the importance of familynurse to develop and to share knowledge and experiences. To conclude can be said that beyond the reach of the objective tracings in the visit, innumerable were the profits acquired in the development of this activity.
\end{abstract}

Keywords: International Educational Exchange. Education, Nursing, Graduate. Patient Care Team.

\section{Resumen}

El presente artículo consiste en un relato de experiencia sobre la visita de estudio realizada en el Canadá a través de la Bourse de Complément de Spécialisation del Faculty Enrichment Program in Brazil, concedida por la Embajada del Canadá en el Brasil. Describe las actividades realizadas durante la visita y presenta el Programa Interdisciplinario de Intervención Precoz. Este programa está basado en la experiencia de intervención por medio del abordaje inscrito en la corriente de la educación para la salud, reconoce que la eficacia de la intervención profesional está estrechamente unida al grado de colaboración establecido entre padres y profesionales y da énfasis a la importancia de la familiaenfermera desarrollar y compartir conocimientos y experiencias. A manera de conclusión se puede decir que más allá del alcance de los objetivos trazados en la propuesta de la visita, fueron innumeras los beneficios en el desarrollo de esa actividad.

Palabras clave: Intercambio Educacional Internacional. Educación de Postgrado en Enfermería. Grupo de Atención al Paciente. 


\section{INTRODUÇÃO}

Durante a realização do Curso de Doutorado em Enfermagem da Escola de Enfermagem Anna Nery/UFRJ, ao discutir maternagem especial, uma das linhas de pesquisa do Núcleo de Pesquisa em Saúde da Mulher (NUPESM), ficamos conhecendo o Programa Interdisciplinar de Intervenção Familiar (PRIFAM) da Universidade de Montreal, no Canadá. Conhecer este programa foi o objetivo da visita de estudo realizada com o contributo da Bourse de Complément de Spécialisation do Faculty Enrichment Program in Brazil, concedida pela Embaixada do Canadá no Brasil.

A proposta básica desse programa é oferecer a oportunidade de visita ao Canadá, por período máximo de quatro semanas, a professores de universidades brasileiras interessados em desenvolver cursos com conteúdos canadenses. Esta visita, centrada na área de interesse do docente, no caso malformações congênitas, visa ao aprimoramento do docente, coleta de subsídios e de bibliografias necessários ao desenvolvimento de cursos já existentes, ou em fase de organização. Uma característica peculiar dos cursos a serem oferecidos é que estes devem comportar pelo menos $50 \%$ de conteúdos relacionados à visita de estudo realizada.

0 processo que culminou nessa experiência teve início em setembro de 2003, quando a Pós-graduação da Escola de Enfermagem Anna Nery/UFRJ divulgou o Programa e o período de inscrições. A partir disso foi elaborado o projeto com a proposta da visita e respectiva justificativa. Com o auxílio da Coordenação da Pós-graduação foi estabelecido contato com professores de universidades canadenses e, a partir disso, construído o roteiro da visita. Com o roteiro definido e o com o aceite de vista das instituições pré-estabelecidas, o projeto, juntamente com os demais documentos solicitados, foi encaminhado à embaixada do Canadá no Brasil, em dezembro do mesmo ano, prazo de encerramento das inscrições.

Em fevereiro de 2004, a embaixada canadense informou que 0 projeto havia sido aprovado em primeira instância e encaminhado para avaliação no Canadá. No mês seguinte chegou o comunicado da concessão da bolsa de estudo para a visita, que foi realizada durante o mês de agosto de 2004, atendendo ao proposto no projeto.

A experiência constituiu-se numa grande oportunidade de aprimoramento técnico-científico, além de manter intercâmbio entre o Brasil e o Canadá, e entre universidades desses dois países.

\section{ATIVIDADES REALIZADAS DURANTE A VISITA AO CANADÁ}

0 objetivo primordial da visita foi conhecer o Programa Interdisciplinar de Intervenção familiar (PRIFAM). Portanto, as atividades foram desenvolvidas em função desse objetivo. Depois de instalada, a autora passou a freqüentar a Faculty of Nursing da Université de Montréal e estudar o Programa com os professores da instituição, particularmente, com o Prof. Dr Michel Perreault, Prof ${ }^{a}{ }^{a}{ }^{a}$ Diane Pechalt e Prof ${ }^{a} D r^{a}$ Hélène
Lefébvre. Foi sugerida a vivência prática, para ambientação e visitas técnicas nos seguintes hospitais: L'hospital de Montreal pour Enfantes e Montreal Children's Hospital. Além desses hospitais, outros Hospitais Infantis foram visitados conforme previsto no cronograma da visita.

0 Hospital Maisonneuve-Rosemont e Hôpital Ste-Justine são referencias para o cuidado infantil. Nestes foram feitas visitas técnicas com o objetivo de conhecer os programas de intervenção e as rotinas do cuidado pediátrico.

Por causa da importância da rede de referência e contrareferência do sistema de saúde comunitário e do sistema hospitalar, foi considerado pertinente conhecer o Cité de la Santé de Laval, tido como um modelo de referência no cuidado domiciliar. Foi visitada, também, a Faculty of Nursing da Université Laval. Na ocasião, esta instituição promoveu uma reunião científica, quando a autora foi convidada a participar da mesa de discussão para a troca de informações, visando ao aprimoramento da assistência de enfermagem à criança hospitalizada e a sua família. Com este mesmo objetivo, foi realizada reunião científica de intercâmbio na Faculty of Nursing da Queen's University.

Nas três instituições de ensino foi possível conhecer e discutir a estrutura curricular dos Cursos de Graduação de Enfermagem, referente à malformação congênita, já que este tema é o foco de uma das categorias analíticas, da tese de doutorado intitulada: Os profissionais de enfermagem frente ao nascimento da criança com malformação congênita, defendida pela primeira autora deste relato.

Isto permitiu uma importante orientação teórica a respeito dos componentes curriculares do curso de Enfermagem, no que tange à malformação congênita. Na Faculty of Nursing, Université de Montreal, foi possível, também, discutir a respeito da estrutura curricular dos cursos de Stricto Sensu.

No retorno ao Brasil, foram realizadas atividades de Extensão Universitária, para divulgar o conhecimento construído na visita-estudo, conforme proposto no projeto. Uma delas foi o evento intitulado "Cuidando da Família e da Criança com Malformação Congênita" realizado em outubro de 2004 na Escola de Enfermagem Anna Nery/UFRJ. 0 evento foi destinado a profissionais e estudantes da área de saúde interessados na pesquisa e assistência ao parto e nascimento de crianças com malformação congênita. Ele contou com a presença da Prof $f^{a}$ Diane Pechalt, professora titular da Faculdade de Ciências de Enfermagem da Universidade de Montreal/Ca, idealizadora do PRIFAM, que se encontrava de passagem pelo Brasil. Na ocasião, foi feito convite aos professores da EEAN para a realização de uma pesquisa comparativa entre Brasil e Canadá a ser desenvolvido conjuntamente por pesquisadores das duas instituições.

\section{CONHECENDO O PRIFAM}

0 Programa Interdisciplinar de Intervenção Familiar (PRIFAM), criado e desenvolvido na Universidade de Montreal, no Canadá, e descrito por Pelchat e Lefébvre ${ }^{1}$,é uma experiência que vem demonstrando significativas contribuições, tanto na 
assistência prestada às famílias que passam por crise decorrente de problemas de saúde de um dos seus membros, como na formação dos profissionais para a efetiva intervenção.

Originalmente, o programa de intervenção precoce visava atender as famílias de crianças malformadas; depois foi ampliado para as famílias de crianças com alguma necessidade especial e, atualmente, é direcionado para todas as famílias que estejam vivendo algum tipo de estresse em função de um problema de saúde, constituindo-se num modelo de cuidado.

0 programa afasta-se dos moldes tradicionais e baseia-se unicamente na experiência da intervenção por meio de sua abordagem, inscrita na corrente da educação para a saúde. Assim, reconhece que a eficácia da intervenção profissional está estreitamente ligada ao grau de colaboração estabelecido entre pais e profissionais, enfatizando a importância de desenvolver competências no estabelecimento de parcerias família-enfermeira, favorecendo a partilha de conhecimentos e experiências.

\section{Fundamentos Teóricos do Programa}

Os fundamentos teóricos do programa, segundo Pechalt², estão inspirados nas seguintes abordagens teóricas: teoria da psicodinâmica da crise no contexto de luto, teoria de estresse e de adaptação, teoria do estresse familiar e teoria dos fundamentos de intervenção familiar. Os objetivos do programa estão centrados nos cinco subsistemas da família:

Individual - conhecer a percepção religiosa de cada um dos pais, oferecer-lhes uma percepção realista e progredir no processo de luto da criança desejada.

Conjugal - ajudar os cônjuges a melhor compreenderem a experiência do outro e se ajudar mutuamente no processo de luto.

Parental - favorecer uma relação de confiança entre os pais e a criança, e favorecer a evolução positiva do apego.

Familiar - favorecer a troca de percepção da situação entre os membros da família, e reconhecer a influência de cada um no processo de adaptação.

Extra-familiar - ajudar os pais a conservar as relações significativas com seu círculo de amigos, utilizando o mais eficazmente possível os recursos do meio e da ajuda dos profissionais de saúde.

\section{Definindo o Programa}

0 PRIFAN é definido como uma associação interdependente de pessoas reconhecidas por suas experiências e seus esforços em perseguir um bem comum. Seus princípios estão envolvidos num conjunto de crenças que gerenciam atitudes e comportamentos que visam à apropriação de competências, autodeterminação e autonomia ${ }^{3}$.

É de suma importância que cada um reconheça as próprias competências e as da outra pessoa; isso vai permitir a autodeterminação pessoal, que consiste em se sentir capaz de assumir a responsabilidade de decidir, de precisar seus objetivos e seu papel.

A ação em parceria entre pais e enfermeiras é estabelecida no primeiro encontro, ao passo de cativar o desejo de cooperar, a partir da ação de compartilhar conhecimentos, habilidades e recursos. Isso contribui para a adaptação de famílias e o bem-estar do profissional por reconhecer os próprios recursos e suas competências mútuas. Os pais dividem suas percepções da situação e seus recursos, interno e externo. Isso Ihes permite apropriar sua competência de fazer emergir um sentimento de confiança.

\section{Intervenções do Programa}

A intervenção estabelecida deve ser integral e considerar a relação com a pessoa e sua família na sua essência ontológica, imprimindo uma consciência ética, moral e espiritual. Nessa perspectiva, o cuidado vai além da doença física e do tratamento; considera as emoç̃̃es como fatores favoráveis ou desfavoráveis na evolução do ser. Assim, a transformação é vista como uma evolução do ser, que não admite como previsível o resultado da experiência de autodeterminação e autonomia.

Nesse programa de intervenção sistemática, há 0 estabelecimento de uma relação de confiança, assegurando este compromisso em toda ação, que é intencional e resulta no cuidado da família. A intervenção consiste em uma série de seis encontros da enfermeira com a família. Dois ou três desses encontros são realizados no hospital; o primeiro, a qualquer hora após o nascimento da criança, e os outros, conforme a necessidade dos pais. A enfermeira acompanha o médico no momento de comunicar aos pais a deficiência da criança, ou encontra os pais imediatamente após a comunicação da malformação. Quatro a seis encontros são no domicílio familiar, durante os seis primeiros meses de vida da criança, mas 0 número de encontros depende da necessidade dos pais.

No curso desses encontros, a enfermeira deve: explorar os fatores que influenciam a percepção dos pais sobre a situação; reforçar conhecimentos que facilitam a vida com a criança; remeter questões sobre assuntos constrangedores, como a intenção com o recém-nascido, e encorajar os pais a expressarem suas emoções diante da situação. Para isso, a enfermeira deve privilegiar certas intervenções, com destaque para a normalização da experiência dos pais e a valorização das habilidades adaptativas de cada um, a apropriação de sentimentos de competência, apoio mútuo dos cônjuges, suporte familiar e utilização dos recursos disponíveis.

Por ocasião dos encontros, a enfermeira e os pais elaboram um plano de trabalho de modo a fazer diferença para o meio, organizando os cuidados a serem oferecidos à criança. Estes são momentos privilegiados para refletir juntamente sobre a situação, compartilhar as respectivas experiências, propiciar que a enfermeira valorize a competência dos pais, discutindo os procedimentos a serem realizados com a criança e determinando o nível de satisfação deles quanto à divisão de tarefas, à tomada de decisões e ao engajamento de cada membro da família.

A cada encontro com a família, a enfermeira faz uma análise de cada subsistema familiar, da intervenção realizada e da aprendizagem, refletindo sobre o funcionamento da família e sobre seu próprio papel na dinâmica familiar. Ela partilha suas reflexões e experiências vividas junto da família com o grupo de enfermeiras do Programa, sistematicamente.

No que se refere à formação e aplicação do PRIFAM, o Programa é destinado à enfermeira de prática avançada em 
perinatologia. No Brasil, corresponderia a enfermeiras obstetras e neonatais. Comporta um conteúdo teórico e um conteúdo prático. 0 primeiro consiste em uma formação intensiva sobre as teorias que sustentam o Programa, os princípios de interdisciplinaridade e de intervenção familiar sistemática junto às familias que vivem uma situação de estresse. Essa formação propicia à enfermeira a oportunidade de refletir sua prática profissional, visto que lhe permite avançar na vivência das famílias. 0 conteúdo prático compreende aplicação do Programa pelas enfermeiras junto às famílias e sua participação nos encontros regulares da equipe de pesquisa e assistência do PRIFAM.

A intervenção das enfermeiras consiste em uma série de encontros com as famílias, que podem variar conforme a necessidade expressada por eles. Os encontros com o grupo de pesquisa e assistência compreendem reuniões semanais, de início, e depois mensais, durante toda a duração de aplicação do Programa. Estes visam suscitar a introspecção das enfermeiras e a reflexão em grupo sobre sua prática, seus valores, suas atitudes, conhecimentos e pré-julgamentos concernentes à família e à deficiência da criança. Há uma troca sobre seus pensamentos, assim há possibilidade de evoluir no plano pessoal. 0 resultado dessa aprendizagem permite uma reciprocidade entre formadoras, enfermeiras e famílias; assim, tanto a família é guiada pela enfermeira, quanto a enfermeira é guiada pela família.

A formação no PRIFAM convida a enfermeira para uma experiência de união com as famílias que vivem um estresse intensivo e prolongado; a comunicar um problema de saúde de um de seus membros; e a caminhar com essa família na sua experiência, desenvolvendo um papel de mediadora, que favoreça aos pais a apropriação de suas competências.

\section{CONCLUSÃO}

À guisa da conclusão desse relato, podemos dizer que para além do alcance dos objetivos traçados na proposta da visita, inúmeros foram os ganhos advindos no desenvolvimento dessa atividade e experiência. Indubitavelmente, esta foi uma oportunidade ímpar, de grande relevância para o aprimoramento profissional e pessoal da docente contemplada pela bolsa. Entre os ganhos advindos dessa experiência destacamos a oportunidade de conhecer o PRIFAM, que proporcionou uma importante instrumentalização teórica e prática para o atendimento da família da criança malformada, e que foi repassado nas atividades de extensão realizadas no Brasil. Acreditamos que essa instrumentalização tenha repercussões positivas na assistência prestada, pois enfatiza a importância da intervenção adequada e precoce nesses casos.

Vale ressaltar que, durante a realização da visita, em determinado momento os dados preliminares da tese de doutorado que estava ainda em construção foram apresentados, e foi possível observar convergência deles com os resultados apresentados na dissertação de mestrado da Prof ${ }^{a}$ Diane Pechalt. Na ocasião, discutiu-se que esta constatação advinha do fato de que o nascimento de uma criança malformada é delicado igualmente em qualquer local de trabalho, porque está relacionado aos aspectos emocionais de cada profissional, determinando sua desenvoltura e a forma como enfrenta as dificuldades; ou seja, são dificuldades pessoais que os profissionais enfrentam.

0 estabelecimento da parceria entre a Faculty of Nursing da Université de Montréal e a EEAN/UFRJ, para 0 desenvolvimento de uma pesquisa científica, foi um ganho importante, que acreditamos ser profícuo para a comunidade científica. A busca do embasamento teórico referente à estrutura curricular dos cursos de Enfermagem das universidades canadenses serviu de fundamentação para a discussão das categorias analíticas da tese de doutorado. Por fim, ter sido contemplada com a bolsa para a realização da visita foi uma importante oportunidade, uma vez que o Canadá é uma referência mundial no cuidado da criança portadora de malformação congênita. E poder vivenciar essa realidade foi muito proveitoso.

\section{Referências}

1. Pechalt D, Lefèbvre $H$. Le PRIFAM: un programme fondé sur le partenariat. L'infermiére du Québec 2001, 9(5) : 26-32.
2. Pechalt D. Lánnonce de la deficience et processus dádaptation de la famille handicap, medecine, éthique. Les Cahiers de l'Afrée 1994, 6(8): 81-88.

3. Pechalt D, Stefanelli RM, Spinks PE. Différences et similitudes dans l'experience des méres et péres d'un enfant ayant deficience. Les Cahiers Internationaux de Psychologie Sociale 2003; 3(5): 73-82. 


\section{Agradecimentos}

Cumpre-nos selar agora nossos agradecimentos à Embaixada do Canadá, no Brasil, que financiou a visita através do Bourse de Complément de Spécialisation do Faculty Enrichment Program in Brazil, o qual, também, parabenizamos pela brilhante iniciativa.

À Faculty of Nursing da Université de Montreal pela disponibilidade e receptividade com que nos acolheu.

À Pós-graduação da Escola de Enfermagem Anna Nery por oportunizar essa experiência através da divulgação da Bourse de Complément de Spécialisation do Faculty Enrichment Program in Brazil, na pessoa da Prof ${ }^{a} \mathrm{Dr}^{\mathrm{a}}$ Rosangela da Silva Santos, por ter divulgado a possibilidade de visita técnica para todos os pós-graduandos e ter estabelecido o contato direto com professores da Universidade do Canadá, solicitando ajuda e indicação de nomes para a preceptoria de todos os interessados na bolsa, sem o que nada seria possível.

\section{Sobre as Autoras}

\section{lêda Maria Ávila Vargas Dias}

Professora Doutora da Faculdade de Enfermagem da Universidade Federal de Juiz de Fora.

\section{Rosangela da Silva Santos}

Professora Titular Doutora em Enfermagem na Escola de enfermagem Anna Nery/ Universidade Federal do Rio de Janeiro. 